\title{
PROTOTYPE ROBOT LINE FOLLOWER ARDUINO UNO MENGGUNAKAN 4 SENSOR TCRT5000
}

\author{
Ridarmin $^{1}$, Fauzansyah $^{2}$, Elisawati $^{3}$, Eko Prasetyo $^{4}$ \\ ${ }^{1,2,3,4}$ Sekolah Tinggi Manajemen Informatika dan Komputer (STMIK) Dumai \\ Jalan Utama Karya Bukit Batrem Kota Dumai kode Pos 28811 \\ e-mail : ridarmin@mail.stmikdumai.ac.id ${ }^{1}$, fauzansyah03@ gmail.com ${ }^{2}$, \\ elisawati06@gmail.com ${ }^{3}$, echiprasetyou1997@ gmail.com ${ }^{4}$
}

\begin{abstract}
ABSTRAK
Sensor merupakan indera bagi robot sehingga dapat mengenali berbagai parameter disekitar lingkungan, seperti robot yang dapat bergerak mengikuti garis atau biasa disebut dengan robot line follower. Robot line follower analog terdiri dari rangkaian analog dalam melacak dan membaca sebuah garis. permasalahan yang dijadikan dasar dalam penelitian ini yaitu pada robot line follower analog hanya terdiri dari rangkaian analog untuk melacak garis serta tidak dapat diprogram, karena robot line follower analog tidak dilengkapi dengan mikrokontroller. Adapun yang menggunakan mikrokontroler tidak dilengkapi dengan perangkat chip programmer dan bootloader sehingga memunculkan ide peneliti untuk merancang dan membuat prototype line follower menggunakan Arduino Uno sebagai pengendali robot. Arduino Uno R3 terdapat papan yang sudah terdapat chip programmer dan bootloader menggunakan IDE Arduino melalui komunikasi kabel USB. Prototype line follower ini menggunakan papan Arduino Uno sehingga dapat diprogram sesuai kebutuhan dan dapat dikembangkan secara cepat. Sehingga kecepatan robot dapat mengikuti garis sesuai dengan lintasan yang di buat.
\end{abstract}

Kata Kunci :Arduino Uno, Robot Line Follower, TCRT5000

\begin{abstract}
Sensors are the senses for robots so they can recognize various parameters around the environment, such as robots that can move along lines or commonly called robot follower lines. An analog line follower robot consists of analog circuits in tracking and reading a line. The basic problem in this research is that analog line follower robots only consist of analog circuits to trace lines and cannot be programmed, because analog line follower robots are not equipped with a microcontroller. As for who uses a microcontroller not equipped with a chip programmer and bootloader device that led to the idea of researchers to design and make a prototype line follower using Arduino Uno as a robot controller. Arduino Uno R3 has a board that already has a programmer chip and bootloader using the Arduino IDE via USB cable communication. This line follower prototype uses the Arduino Uno board so that it can be programmed as needed and can be developed quickly. So the speed of the robot can follow the line by the trajectory made.
\end{abstract}

Keywords: Arduino Uno, Robot Line Follower, TCRT5000

\section{PENDAHULUAN}

Robot merupakan sebuah alat yang bisa melakukan pekerjaan sesuai dengan program yang di perintahkan di dalam robot tersebut. Sistem kontrol robot yang paling utama adalah input. Input dari robot merupakan sekumpulan data dan diproses menjadi sebuah informasi. data yang didapat dari sensor yang di tanamkan pada robot. Robot Line Follower (Robot
Pengikut Garis) Robot line follower analog terdiri dari rangkaian analog untuk melacak garis serta tidak dapat diprogram sesuai kebutuhan, karena robot line follower analog tidak dilengkapi mikrokontroller. Adapun yang menggunakan mikrokontroler tidak dilengkapi perangkat chip programmer dan bootloader. selain itu Prototype robot line follower ini dapat dijadikan sebagai media pembelajaran untuk 
I N F O R M A I I A

Jurnal Informatika, Manajemen dan Komputer, Vol. No. , Agustus 2019

eISSN : 2580-3042

pISSN : 1979-0694

meningkatkan pemahaman mahasiswa dalam mempelajari pembuatan robot. Dari latar belakang diatas maka diangkat sebuah judul "Prototype Robot Line Follower Arduino Uno Menggunakan 4 Sensor Garis TCRT5000". Untuk membuat sebuah robot yang dapat diprogram menggunakan papan Arduino Uno dan bergerak mengikuti garis dengan menggunakan 4 sensor.

Adapun tujuan yang terdapat pada penelitian ini yaitu: (a) Merancang prototype Robot line follower dengan konsep robot mobil berbasis Arduino Uno menggunakan 4 sensor garis TCRT5000, (b) Membuat prototype Robot line follower berbasis Arduino Uno yang dapat diprogram menggunakan Software IDE Arduino sesuai dengan kebutuhan, dan (c) Memudahkan proses memprogram dan proses mengupload karna papan Arduino Uno sudah memiliki chip program dan bootloader serta komunikasinya hanya menggunakan kabel USB.

Adapun manfaat dari penelitian ini adalah:

a. Prototype Robot line follower ini menggunakan papan Arduino Uno sehingga mudah untuk diprogram dan dapat dikembangkan secara cepat.

b. Bermanfaat bagi peneliti berikutnya sebagai referensi dalam mengembangkan Robot line follower berbasis Arduino Uno.

\section{a. Pengertian Sistem}

Menurut Bodnar dan Hoowood (2009) sistem adalah suatu jaringan kerja dari prosedur-prosedur yang saling berkaitan, berkumpul bersama-sama untuk melakukan suatu kegiatan atau untuk menyelesaikan suatu sasaran tertentu. Dari beberapa pendapat di atas dapat disimpulkan bahwa sistem adalah seperangkat elemen atau jaringan kerja dari prosedur-prosedur yang saling berkaitan dan saling bekerja sama membentuk suatu jaringan kerja untuk mencapai sasaran atau tujuan tertentu. (Oktafianto, 2016:1)

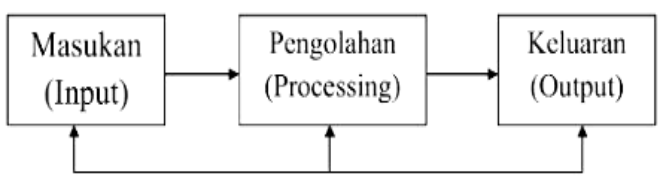

Gambar 1. Model Sistem

Sumber : (Oktafianto, 2016:1)

\section{b. Pengertian Prototyping}

Menurut (Adi Fitra Andikos dan Yesi Gusteti, 2016) Prototype merupakan suatu metode dalam pengembangan sistem yang

menggunakan pendekatan untuk membuat sesuatu program dengan cepat dan bertahap sehingga segera dapat dievaluasi oleh pemakai. Prototype mewakili model produk yang akan dibangun atau mensimulasikan struktur, fungsional, dan operasi sistem. (Michael \& Gustina, 2018)

\section{c. Pengertian Mikrokontroler}

menurut Bishop (2002) Mikrokontroller adalah rangkaian terpadu tunggal, dimana semua blok rangkaian yang kita jumpai sebagai unit-unit terpisah di dalam sebuah komputer digabungkan menjadi satu. (Michael \& Gustina, 2018)

\section{d. Pengertian Komponen Elektronika}

Dalam bidang elektronika, komponen diartikan sebagai elemen terkecil dari rangkaian/sistem elektronik berdasarkan respon output terhadap inputnya.(Hakiem, 2015)

\section{e. Pengertian Arduino}

Arduiono adalah kit elektronik atau papan rangkaian elektronik open source yang didalamnya terdapat komponen utama, yaitu sebuah chip mikrokontroller dengan jenis $A V R$ dari perusahaan Atmel. Mikrokontroller itu sendiri adalah chip atau IC (integrated circuit) yang biasa di program dengan komputer tujuan menanamkan program pada mikrikontroler adalah agar rangkaian elektronik dapat membaca input, memproses input tersebut dan kemudian menghasilkan output sesuai yang diinginkan. (Rosmanila, Radillah, \& Sofiyan, 2018)

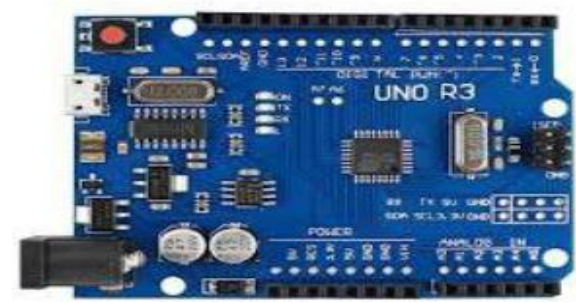

Gambar 2. Arduino Uno

Sumber : (Rosmanila et al., 2018)

\section{f. Pengertian IDE Arduino}

menurut (Adriansyah \& Hidyatama, 2013). didalam jurnal Teknologi Elektro, Arduino UNO adalah sebuah board mikrokontroler yang didasarkan pada ATmega328. Arduino UNO mempunyai 14 pin digital input/output (6 di antaranya dapat digunakan sebagai output PWM), 6 input analog, sebuah osilator Kristal $16 \mathrm{MHz}$, sebuah koneksi USB, sebuah power jack, sebuah ICSP header, dan sebuat tombol 
I N F O R M A I I A

Jurnal Informatika, Manajemen dan Komputer, Vol. No. , Agustus 2019

eISSN : 2580-3042

pISSN : 1979-0694

reset. Arduino UNO memuat semua yang dibutuhkan untuk menunjang mikrokontroler, mudah menghubungkannya ke sebuah computer dengan sebuah kabel USB atau mensuplainya dengan sebuah adaptor AC ke DC atau menggunakan baterai untuk memulainya(Linarta \& Nurhadi, 2018).

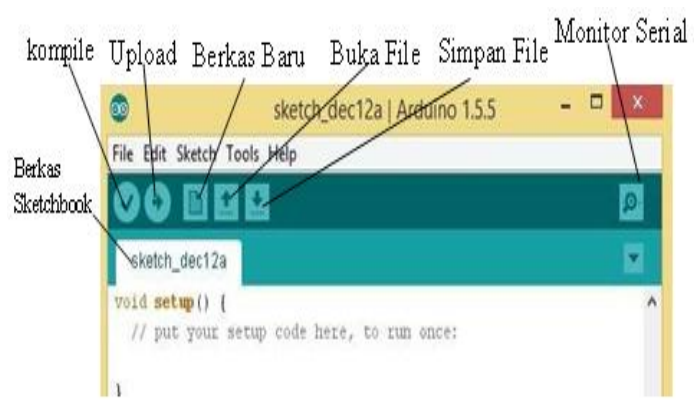

Gambar 3. Tampilan Software IDE Arduino Sumber : (Linarta \& Nurhadi, 2018)

\section{g. Pengertian Sensor Pendeteksi Garis}

Sensor pendeteksi garis sebenarnya bisa dibuat dengan menggunakan LED, LDR, dan komparator untuk mengambil keputusan adanya garis atau tidak. Namun, untuk mempermudah implementasi, modul yang ditujukan untuk mendeteksi garis bisa menjadi pilihan. Salah satu modul untuk mendeteksi garis dinamakan IR line tracking sensor TCR5000 YL-54. Sensor pendeteksi garis tersebut menggunakan inframerah untuk mendeteksi keberadaan garis. Oleh karena itu, sensor ini dapat digunakan pada robot pengikut garis (line follower). (kadir, 2018:221)

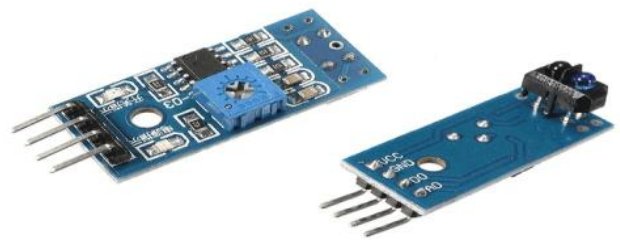

Gambar 4. IR line Tracking Sensor TCR5000 Sumber (kadir, 2018:221)

\section{h. Pengertian Driver Motor}

Pengendalian motor dapat dilakukan dengan menggunakan IC yang ditujukan sebgai motor driver. Salah satu IC yang bisa digunakan adalah ULN2003. Ic ini memiliki 16 pin dan dapat digunakan untuk mengatur tujuh motor DC.(Kadir, 2018:189)

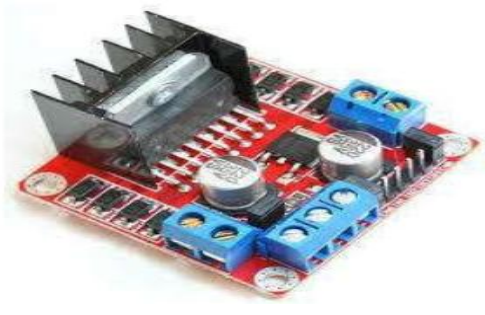

Gambar 5. Motor Driver L298N

Sumber : ( Lulu, F., \& Rohmanu, A. , 2018)

i. Pengertian (LCD) Liquid Criystal Display Liquid Crystal Display (LCD) merupakan perangkat (device) yang sering digunakan untuk menampilkan data selain menggunakan seven segment. LCD berfungsi sebagai salah satu alat komunikasi dengan manusia dalam bentuk tulisan/ gambar. Untuk menghubungkan microcontroller dengan LCD dibutuhkan konfigurasi antara pin-pin yang ada di LCD dengan Port yang ada di mikrokontroller. (Muhammad Yusuf et al, 2016)

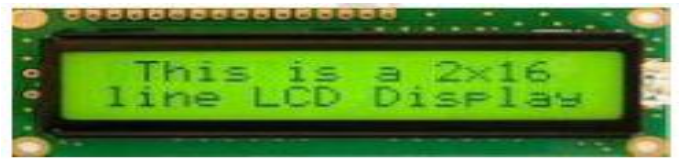

Gambar 6. LCD 2 x 16

Sumber : (Yusuf, M., Isnawaty, \& Ramadhan, R. , 2016)

\section{METODE PENELITIAN}

Didalam metode penelitian ini terdapat kerangka kerja dari urutan-urutan yang tersusun secara sistematis agar tujuan dari penelitian menjadi lebih baik.

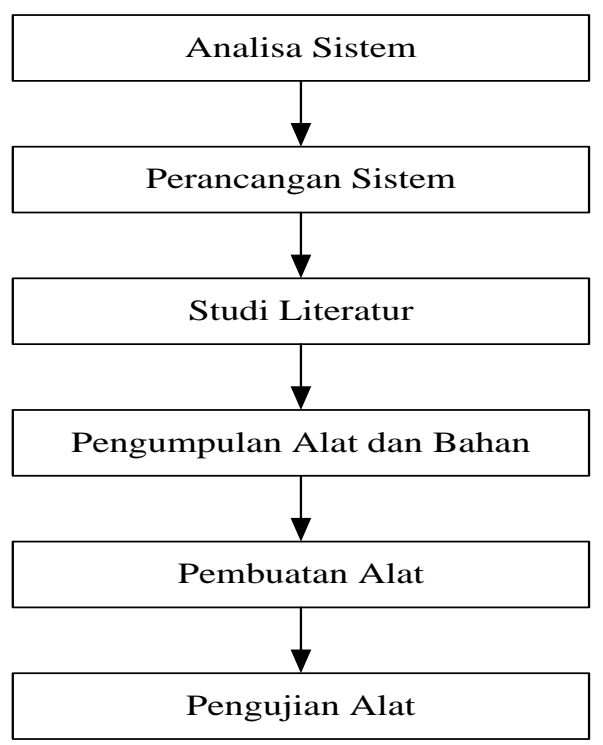

Gambar 7. Kerangka kerja 
I N F O R M A T I K A

Jurnal Informatika, Manajemen dan Komputer, Vol. No. , Agustus 2019

eISSN : 2580-3042

pISSN : 1979-0694

Berdasarkan gambar 7, maka dapat dijabarkan urutan - urutan langkah kerja sebagai berikut:

1. Analisa Sistem

Tahapan ini merupakan mengindentifikasi masalah, mengevaluasi masalah sehingga permasalahan tersebut dapat diselesaikan.

2. Perancangan sistem

Tahapan ini melakukan perancangan alat dimana memodelkan sistem yang akan di bangun dan menentukan aplikasi yang digunakan dalam membuat Prototype Robot Line Follower menggunakan Arduino Uno.

3. Studi Literatur

Dalam penelitian ini penulis membutuhkan literature, buku, internet, referensi maupun jurnal sebagai pendukung dalam memecahkan masalah serta membangun alat Prototype Robot Line Follower Arduino Uno dalam penelitian ini.

4. Alat dan Bahan

Tahapan ini merupakan pengumpulan alat dan bahan yang digunakan untuk pembuatan Prototype Robot Line Follower Arduino Uno Menggunakan 4 Sensor TCRT5000. Seperti kit Arduino Uno, sensor garis, dan sebagainya.

5. Pembuatan Alat

Tahapan ini merupakan memulai merangkai atau merancang alat dengan bahan-bahan yang sudah disiapkan. Sesuai dengan logika yang udah di pikirkan untuk membuat Prototype Robot Line Follower Arduino Uno Menggunakan 4 Sensor TCRT5000. Seperti merangkai satu demi satu alat atau bahan yang sudah kita sediakan kemudian setelah di rangkai masukan logika kedalam Arduino uno sehingga Robot bisa bekerja.

6. Pengujian Alat

Setelah alat yang dibuat selesai dirancang langkah selanjutnya melakukan pengujian terhadap alat ini apakah alat yang di rancang berjalan sesuai dengan tujuan penelitian. Seperti pengujian terhadap alat dimana Arduino Uno telah menerima logika untuk bisa menggerakan Robot tersebut.

\section{HASIL DAN PEMBAHASAN}

Robot line follower perangkat kerasnya terdiri dari arduino Uno, rangkaian catu daya, rangkaian sensor TCRT5000, rangkaian driver motor L298N dan rangkaian LCD. Berikut hasil dari rangkaian secara keseluruhan:

a. Perancangan prototype Robot line follower Secara Keseluruhan.

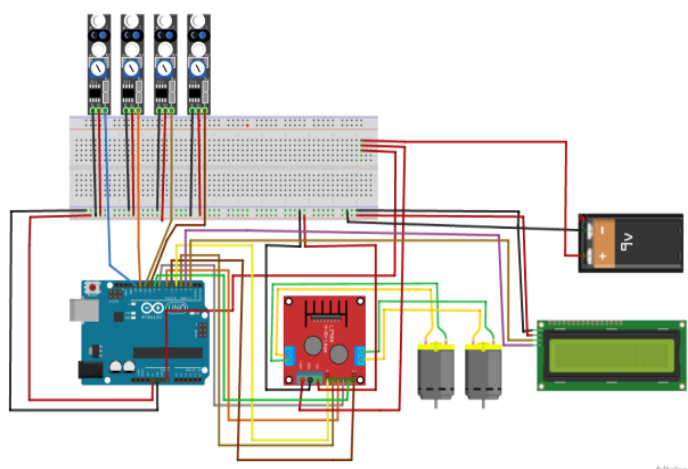

Gambar 8. Perancangan prototype line follower Secara Keseluruhan

Gambar diatas merupakan perancangan rangkaian prototype Robot line follower secara keseluruhan. Pada gambar, tampak hubungan antara komponen perangkat keras, yaitu Arduino Uno dan sensor garis TCRT5000, Arduino Uno dan LCD 16x2, Arduino Uno dan Modul Driver L298N dan Modul Driver L298N ke Motor DC.

\section{b. Desain Rancangan Robot}

Desain perancangan Robot menggambarkan rancangan alat yang sudah dibuat, adapun desain rancangan prototype robot line follower sebagai berikut:

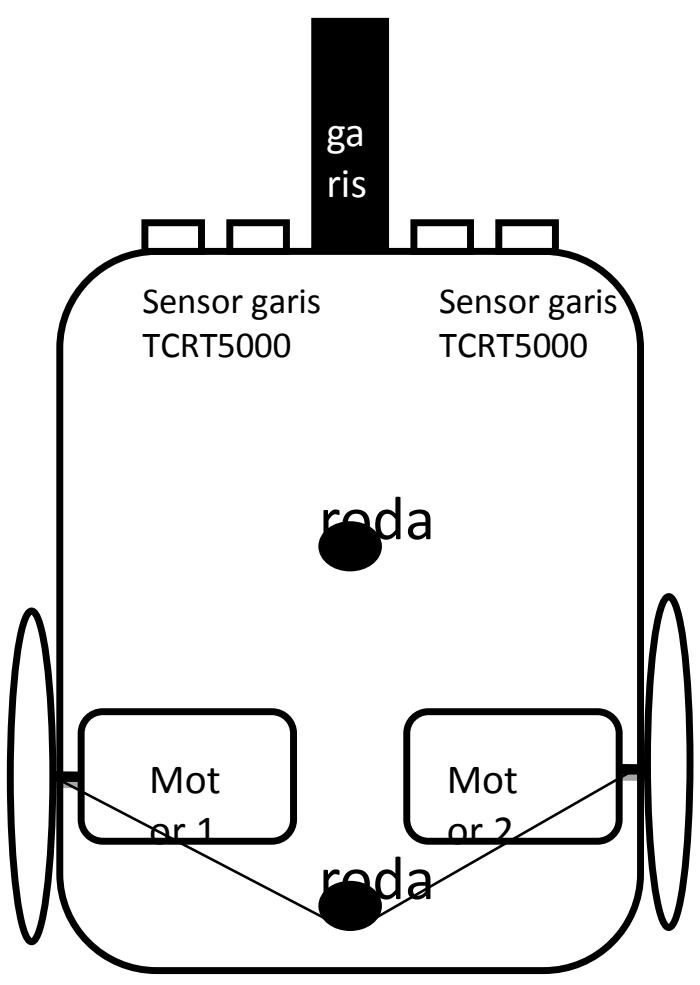

Gambar 9. Desain Rancangan robot 
IN F ORMA T I K A

Jurnal Informatika, Manajemen dan Komputer, Vol. No. , Agustus 2019

eISSN : 2580-3042

pISSN : 1979-0694

\section{c. Hasil Rangkaian Perangkat Keras (Hardware)}

Perangkat keras terdiri dari arduino Uno, rangkaian catu daya, rangkaian sensor TCRT5000, rangkaian driver motor L298N dan rangkaian LCD. Berikut hasil dari rangkaian secara keseluruhan:

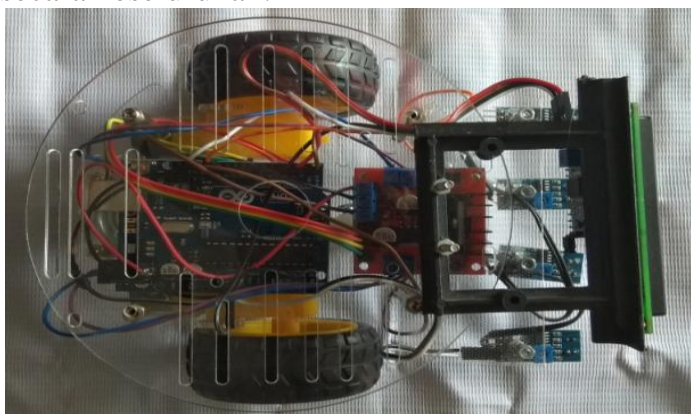

Gambar 10. Tampilan Robot Pada Bagian Atas

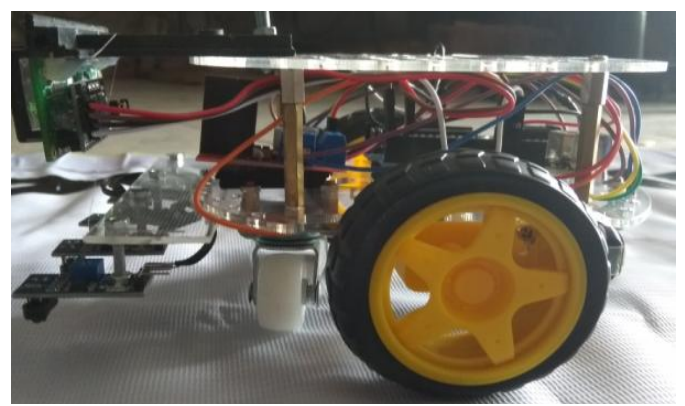

Gambar 11. Tampilan Robot Pada Bagian samping

\section{d. Hasil Rangkaian Arduino Uno}

Arduino Uno merupakan pengendali dari alat tersebut, yang telah tergabung menjadi minimum sistem. Arduino Uno bertugas pengendali untuk memprogram dan mengupload koding robot line follower, mengaktifkan driver motor L298N, untuk menggerakan motor DC yang telah terdeteksi oleh sensor TCRT5000, dan menampilkan informasi gerak robot line follower pada LCD. Rangkaian Arduini Uno terdapat pada Gambar berikut:

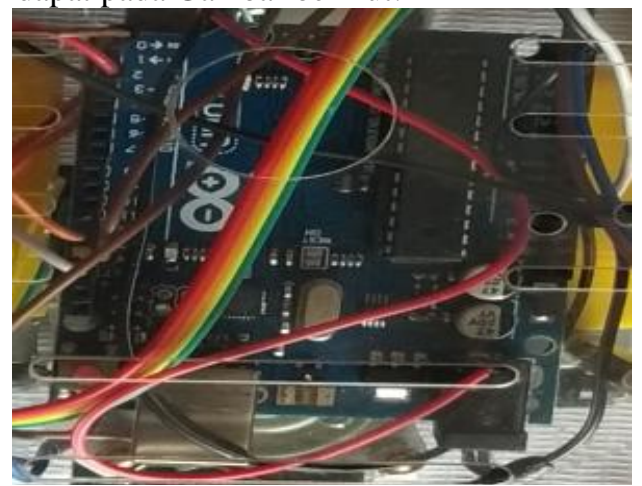

Gambar 12. Hasil Rangkaian Dengan ArduinoUno

\section{e. Hasil Rangkaian Sensor TCRT5000}

Pada rangkaian sensor TCRT5000 setiap pin $S$ menghubungkan dengan pin Analog pada Arduino Uno pada pin $13,12,11,10$. sehingga data keluaran sensor TCRT5000 yang berupa sinyal yang bernilai $1 / 0$. Ground (G) menghubungkan dengan pin ground pada Arduino Uno, $\mathrm{V}+$ menghubungkan dengan pin $5 \mathrm{~V}$ pada Arduino Uno. Hasil rangkaian dengan sensor TCRT5000 tersaji pada Gambar berikut:

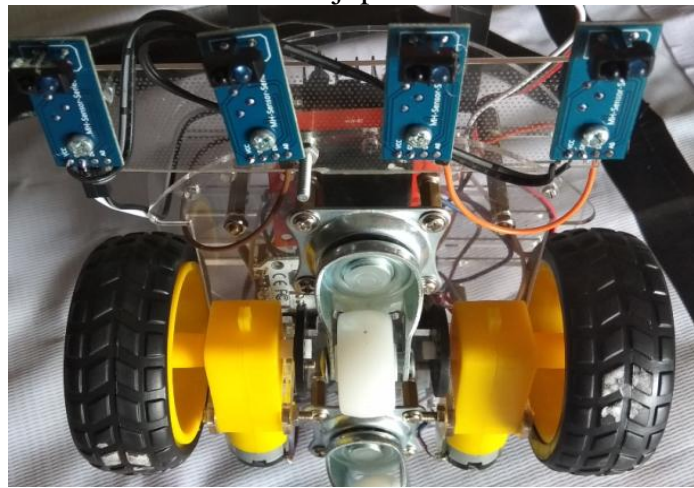

Gambar 13. Hasil Rangkaian Sensor TCRT5000

\section{f. H asil Rangkaian LCD 16X2}

LCD dot matriks karakter 2x16 untuk tampilan informasi pada robot line follower dan nilai yang dibaca sensor TCRT5000. Rangkaian LCD terdiri dari I2C yang digunakan untuk menconvert pin pada Arduino Uno dengan menggunakan modul I2C ini maka diperlukan 4 pin saja untuk dihubungkan ke Arduino Uno yang terdiri dari pin SCL, SDA,GND dan VCC dari 16 pin pada LCD. Pada pin SCL LCD menghubungkan ke pin 3 arduino uno, pin SDA menghubungkan ke pin 2 Arduino Uno, pin GND lcd menghubungkan pada pin GND Arduino Uno dan pin VCC LCD menghubungkan pada pin $5 \mathrm{~V}$ Arduino Uno. Adapun hasil dari rangkaian lcd 16x2 tersaji pada lampiran berikut.

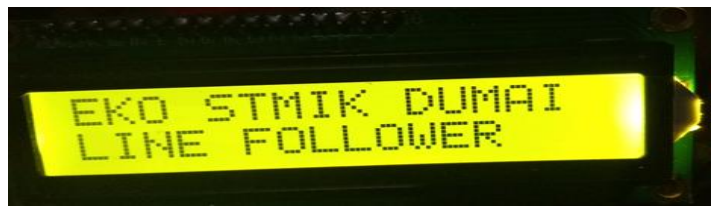

Gambar 14. Hasil Rangkaian Sensor LCD 16x2

\section{g. Hasil Rangkaian Driver motor L298N}

Pada penelitian ini digunakan driver motor L298N untuk mengontrol gerak motor DC pada robot line follower. Ketika sensor garis TCRT5000 mendeteksi adanya lintasan garis lalu data tersebut dikirimkan ke Arduino Uno untuk diproses dan memberikan perintah agar motor driver 1298n untuk menggerakan motor 
I N F O R M A T I K A

Jurnal Informatika, Manajemen dan Komputer, Vol. No. , Agustus 2019

eISSN : 2580-3042

pISSN : 1979-0694

DC. Adapun hasil dari rangkaian driver motor L298N tersaji pada lampiran berikut :

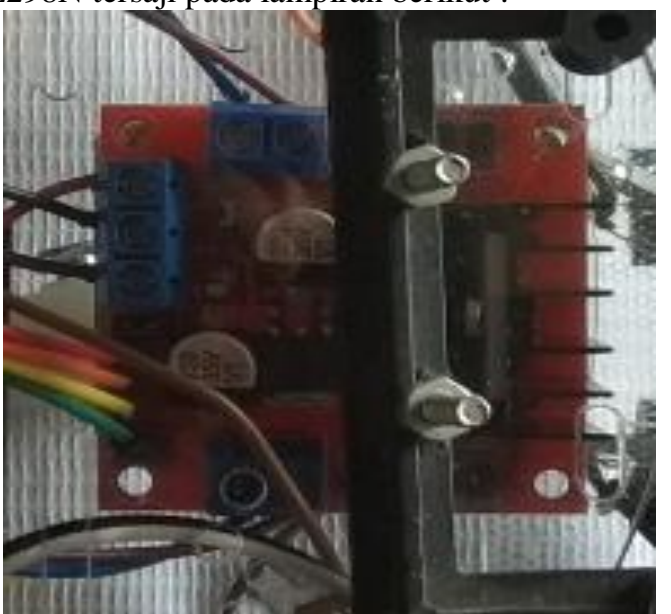

Gambar 15. Hasil Rangkaian Driver Motor L298N

\section{h. Hasil Perangkat Lunak (Software)}

Software ini berfungsi untuk memprogram robot line follower. Bahasa yang digunakan setara dengan bahasa $\mathrm{C}$ yaitu menggunakan software IDE Arduino 1.8.5. Program yang dibuat adalah cara robot dalam mendeteksi garis dan bergerak mengikuti garis lintasan tersebut dan menampilkan informasi gerak pada robot pada LCD.

\section{i. Hasil Perancangan Perangkat Lunak (Software) pada Arduino Uno}

Arduino Uno yang digunakan ini telah tertanam bootloader untuk menangani komunikasi serial/USB dengan komputer. Pilihan serial port yang digunakan board Arduino Uno terdapat pada menu Tools $\rightarrow$ Serial Port. Pilihan serial port pada software Arduino 1.8.5 terdapat pada Gambar 18, Pilihan board Arduino yang dipakai terdapat pada menu Tools $\rightarrow$ Board. Pilihan board pada software Arduino 1.8.5 terdapat pada Gambar 16 sebagai berikut:

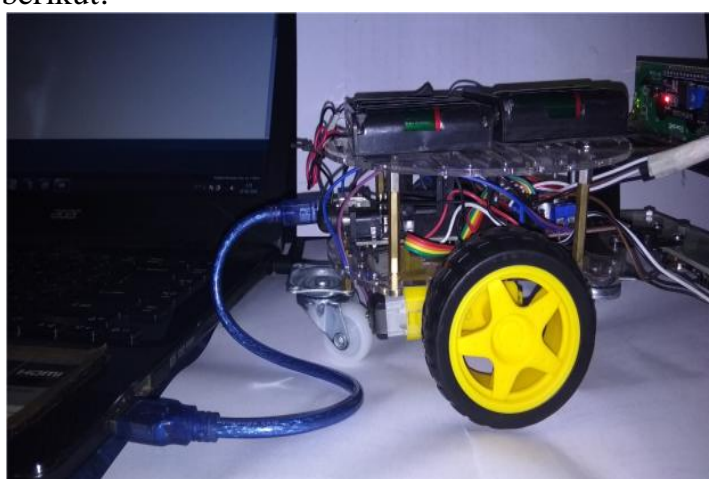

Gambar 16. Komunikasi Arduino Uno Menggunakan Kabel Usb

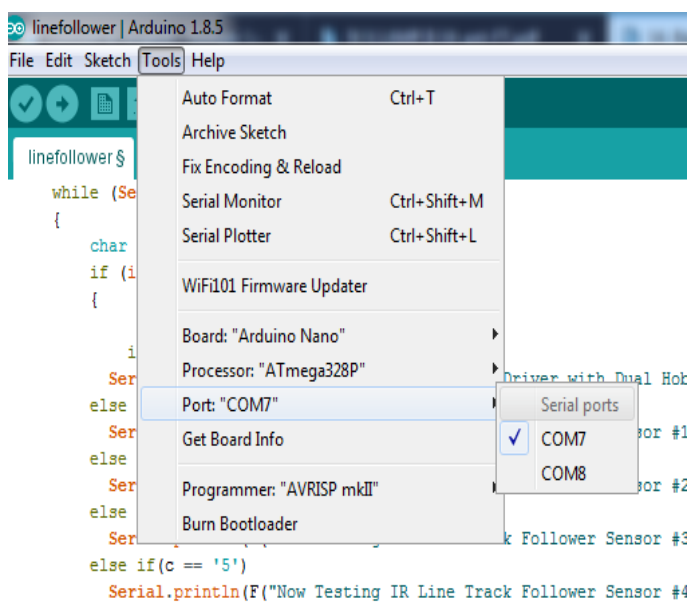

Gambar 17. Pilihan Serial Port Pada Software Arduino 1.8.5

Program yang telah diverifikasi dengan cara menekan verify. Jika tidak terdapat error pada program, program tersebut dapat di-upload ke arduino uno dengan menekan tombol upload. Tombol verify, save, dan upload telah tersaji pada software Arduino seperti pada Gambar 18 dan Gambar 19.

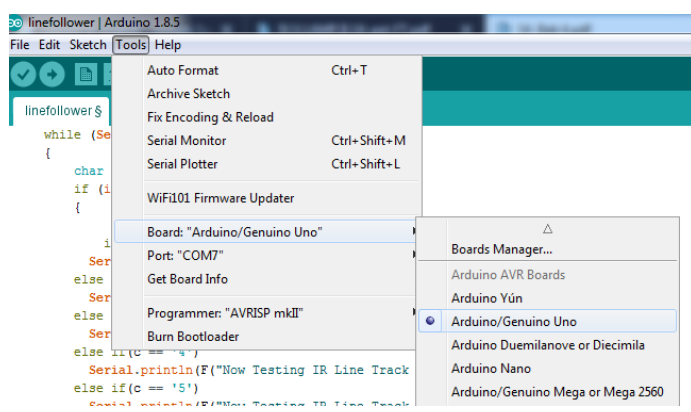

Gambar 18. Pilihan Board Pada Software Arduino 1.8.5

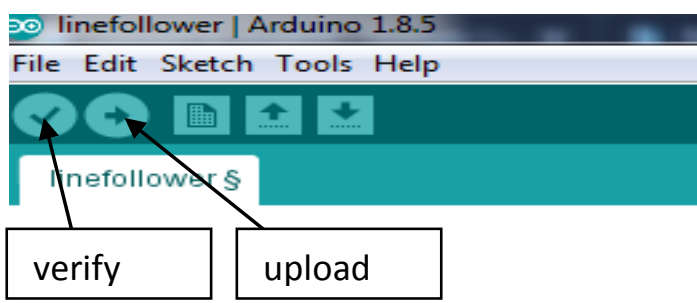

Gambar 19. Tombol Verify Dan Upload Yang Tersedia Pada Software Arduino 1.8.5

\section{j. Hasil Pengujian Keseluruhan Robot Line Follower}

Pada penelitian ini uji keseluruhan robot digunakan untuk mengetahui kinerja robot ketika telah disatukan dengan komponen seperti Arduino Uno, Sensor TCRT5000 Driver Motor 
IN F ORMA T I K A

Jurnal Informatika, Manajemen dan Komputer, Vol. No. , Agustus 2019

eISSN : 2580-3042

pISSN : 1979-0694

L298N, Lcd, Motor Dc untuk dapat mendeteksi dan bergerak mengikuti garis lintasan.

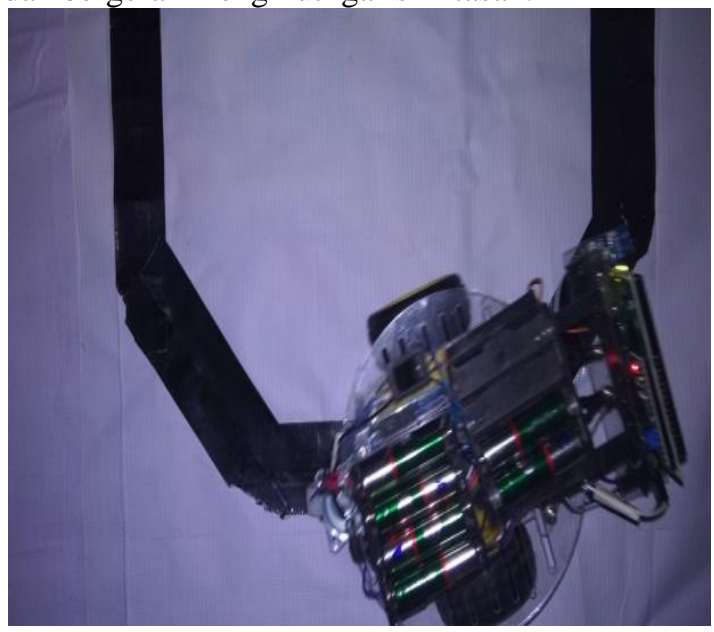

Gambar 20. pengujian Robot Line Follower

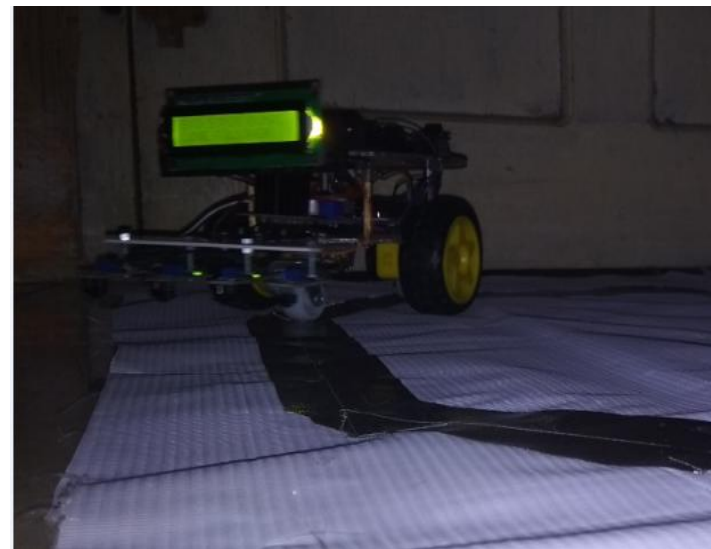

Gambar 21. pengujian Robot Line Follower

Pada penelitian ini prototype Robot line follower berbasis Arduino Uno untuk membuat sebuah robot yang dapat bergerak mengikuti garis dan dapat diprogram sesuai kebutuhan telah berhasil dibangun. Hal ini dapat dilihat bahwa perangkat keras (hardware) dari robot line follower mendukung robot sesuai dengan fungsinya yang terdiri dari Arduino Uno, rangkaian sensor TCRT5000, rangkaian driver motor L298N, rangkaian LCD. Arduino uno terdiri dari program pembacaan garis lintasan, menggerakan motor DC, tampilan infromasi robot melalui LCD telah berhasil untuk di program pada rangkaian hardware menggunakan software IDE Arduino 1.8.5.

\section{KESIMPULAN}

Dengan merancang dan membuat serta melakukan Pengujian robot line follower dilakukan di atas garis gelap/hitam dengan latar belakang terang/putih dapat ditarik kesimpulan yaitu :

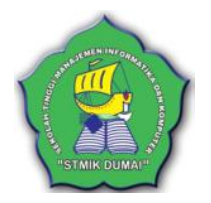

1. Hasil rancangan prototype robot line follower Arduino Uno mengggunakan 4 sensor tcrt5000 telah berhasil dengan baik.

2. Prototype robot line follower ini mudah untuk dikembangkan dengan cepat karena mendukung berbagai modul dan sensor.

3. Kecepatan robot dalam mengikuti garis dipengaruhi oleh bentuk lintasan garis dan tegangan motor DC sebagai penggerak.

\section{REFERENSI}

Hakiem, I. (2015). Elektronics Design \& Repair. Malang: Pt. Tokoteknologi Mikroelektronik Nusantara.

Linarta, A., \& Nurhadi. (2018). Aplikasi Bel Sekolah Otomatis Berbasis Arduino Dilengkapi Dengan Output Suara. Informatika, Manajemen Dan Komputer, 10(2), 1-7. Retrieved From Http://Www.Ejournal.Stmikdumai.Ac.Id/I ndex.Php/Path/Article/View/108/46

Lulu, F., \& Rohmanu, A. (2018). Sistem Kontrol Pendingin Ruangan Menggunakan Arduino Web Server Dan Embedded Fuzzy Logic Di Pt. Inoac Polytechno Indonesia. Jurnal Informatika Simantik, 3(1), 21-27.

Michael, D., \& Gustina, D. (2018). Rancang Bangun Prototype Monitoring Kapasitas Air Pada Kolam Ikan Secara Otomatis Dengan Menggunakan Mikrokontroller Arduino. Jurnal Ikra-Ith Informatika, 3(2), 59-66.

Oktafianto, M. M. (2016). Analisis Dan Perancangan Sistem Informasi Menggunakan Model Terstruktur Dan Uml. Yogyakarta: Andi.

Rosmanila, Radillah, T., \& Sofiyan, A. (2018). Informatika: Jurnal Informatika, Manajemen Dan Komputer, 10(1), 32-38. Https://Doi.Org/Http://Dx.Doi.Org/10.367 23/Juri.V10i1.90

Yusuf, M., Isnawaty, \& Ramadhan, R. (2016). Implementasi Robot Line Follower Penyiram Tanaman Otomatis Menggunakan Metode ProportionalIntegral-Derivative Controller (Pid). Jurnal Semantik, 2(1), 111-124. 